\title{
AC 2009-1009: WHAT DOES MY CAR AM RADIO HAVE TO DO WITH LEARNING ELECTRONICS?
}

\section{Oscar Ortiz, LeTourneau University}

\section{Paul leiffer, LeTouneau University}

Paul R. Leiffer is a professor in the School of Engineering and Engineering Technology at LeTourneau University, where he has taught since 1979. He received his B.S.E.E. from the State University of New York at Buffalo and his M.S. and Ph.D. degrees from Drexel University. Prior to joining the faculty at LeTourneau, he was involved in cardiac cell research at the University of Kansas Medical Center. His professional interests include bioinstrumentation, digital signal processing, and engineering ethics. Email: paulleiffer@letu.edu 


\section{What does my car AM radio have to do with learning Electronics?}

\section{Introduction}

During the past two years a one semester long electronics project have been added to the Electronics' Lab curriculum to enhance students learning of basic electronic components. Students who enroll in the electronics' lab, simultaneously enroll into the analog electronics lecture which is a three credit hour course combined with the two-credit-hour lab. Both courses are required for students majoring in the electrical and computer engineering concentrations. Our expectation is that after taking both courses students had learned the theory and application of such components as diodes, Zener diodes, NPN and PNP transistors, MOSFETs, SCR's Diacs, Triacs, and optoelectronic devices.

Project-based learning develops the ability of the students to work in interdisciplinary teams. Projects carried out by interdisciplinary teams are not only an expectation of industry but also have become a required outcome of the ABET engineering criteria. A series of curriculum tools have been developed at our school to ensure that students will have a measure of success in project team work [1] Project-based learning is an instructional method that demands from the student acquisition of critical knowledge, problem solving proficiency, self-directed learning strategies, and team participation skills [2]

During the 2007 fall semester the students studied and implemented FM transmitters and FM receivers as part of their project-based learning experience. For the 2008 fall semester project students studied, designed and implemented AM transmitters and AM receivers. The main challenges that the students faced in the 2008 Project-based learning project were: a) an AM transmitter or receiver design of their own, b) intensive study and research of AM modulators, oscillators, mixers, frequency multipliers and other RF circuits, since electronic communication circuits are studied in detail a semester later in a second electronic course and RF theory is introduced a year later in the Communication course.

Effects on student learning concerning the concepts and applications of the studied electronics components were measured during the semester using quizzes and tests and at the end of the semester students completed a survey. The conclusions of this project and an evaluation between this year results and the previous years are presented in this paper. Improvement of the student learning through hands on projects may prompt the implementation of other projects that may include multidisciplinary collaboration, integration of projects between classes, projects across concentrations, and integration of semester projects into a larger unifying project that may assemble student's learning from the freshman to the senior year.

\section{Background}

To provide a hands-on experience to the electronic lectures a set of learning oriented, predefined labs are incorporated in a two-hour lab course: EEGR 3112 Electronic Lab. 
By the end of the semester, after taking both the electronics lecture and the lab, students are expected to have theoretical knowledge of, and application experience with such components as diodes, Zener diodes, NPN and PNP transistors, operational Amplifiers, low pass, high pass and band pass filters, MOSFETs, SCR's Diacs, Triacs, and optoelectronic devices.

To further enhance the student's understanding of the basic analog electronic components and to allow the integration of knowledge from previous courses, as well as to incorporate the research of topics from future courses, project based learning experiments in the form of short term projects, have been added to the electronic labs. Through these projects the students are expected to design and develop an AM/FM radio transmitter or receiver circuit much earlier than they are prepared to handle them; since electronic communication circuits are studied in detail a semester later in the second electronic course and RF theory is introduced a year later in the communication courses.

A project-based learning experience was introduced in the fall semester of 2006 into the 2 credit hour Electronics I lab [3]. In this exercise the students were given the opportunity to propose and work on projects of their personal interest

In the fall semester of 2007, a second project-based learning experience was assigned into the 2 hour credit Electronics lab. The topic of the project was chosen by the instructor. This project was designed to prepare the stage for the student to discover how the electronic components studied in class, can be placed together in an FM circuit to work as signal Amplifiers, local oscillators, FM modulators, FM demodulators, frequency multipliers, FM mixers, FM detectors, and audio power Amplifiers. The results of this year PBL experience showed an improvement in the student's learning, but we were not still satisfied, since the project was lacking on the design of the actual transmitter/ receiver circuit [4]

In the fall semester of 2008, a third project-based learning experience was assigned into the 2 hour credit Electronics lab. The project topic chosen by the instructor was the design and implementation of an AM transmitter or an AM receiver circuit. Through this project we were expecting the student to discover how the electronic components studied in class, can be placed together in an AM circuit to work as signal Amplifiers, local oscillators, AM modulators, AM demodulators, frequency multipliers, AM mixers, AM detectors, and audio power Amplifiers.

This project had the following objectives:

Provide students with the opportunity to:

a) Apply the concepts learned from previous courses, especially Circuits I and circuits II,

b) Apply the concepts learned from their concurrent Electronics lectures and predefined lab experiments, 
c) Challenge them to research, study and apply concepts from future course such as electronic communication circuits and RF theory.

d) Allow student to work in teams.

This paper presents the results of our analog electronics 2008 AM transmitter/receiver project.

\section{Methodology}

Short introduction to the methodology

The electronics lecture and Lab experiments are scheduled into a fifteen weeks Fall semester. The PBL project schedule was:

- First week:

O Initial presentation of the AM project to the students by the instructor.

$\circ$ Organized students in groups of five to six members: half of the groups to work on an AM transmitter circuit and the other half of the groups to work on an AM receiver circuit.

- Second to third week:

○ Homework assignment: to study AM communication theory

- Researched assignment: to look for AM transmitter and receiver circuits and their implementations.

- Fourth week:

- First draft of AM transmitter circuit design,

- First draft of AM receiver circuit design.

- Fifth week:

$\circ$ Final AM transmitter circuit design,

$\circ$ Final AM receiver circuit design.

- Sixth week:

- AM transmitter and AM receiver parts were ordered.

- Eight to tenth week:

○ Students were given free access to work in the university's electronic labs at their own pace. Only one lab period from the scheduled labs was assigned for the AM projects.

- Students soldered and tested their AM transmitter and receiver circuits. kits

- Eleventh to twelfth week

- All teams performed a system functional analysis and testing and presented a report of their findings and calculations.

- Students prepared a power point presentation.

○ Project presentations

\section{The AM transmitter circuit}


The requirements for the design of the AM circuits were straight forward: A transmitter capable of transmitting at a frequency between $550 \mathrm{KHZ}$ to $650 \mathrm{KHZ}$, Amplifier stages built using BJT's (bipolar junction transistors) only, capable of running from a 9 volt battery with an output power between $100 \mathrm{mw}$ to $500 \mathrm{mw}$ to comply with the FCC transmission output power limitations.

The design of the AM transmitter circuit was divided into four major sections. Modules of each section were designed and developed separately. Once each individual module was working, the students had to interconnect all the modules together.

The main section or modules of the AM transmitter were:

- Input audio and signal Amplification

- Local oscillator circuit

- AM modulator/mixer circuit

- Output Amplification and antenna coupling

Figure \# 1 shows a picture of one of the transmitter circuits with a circular loaded antenna.

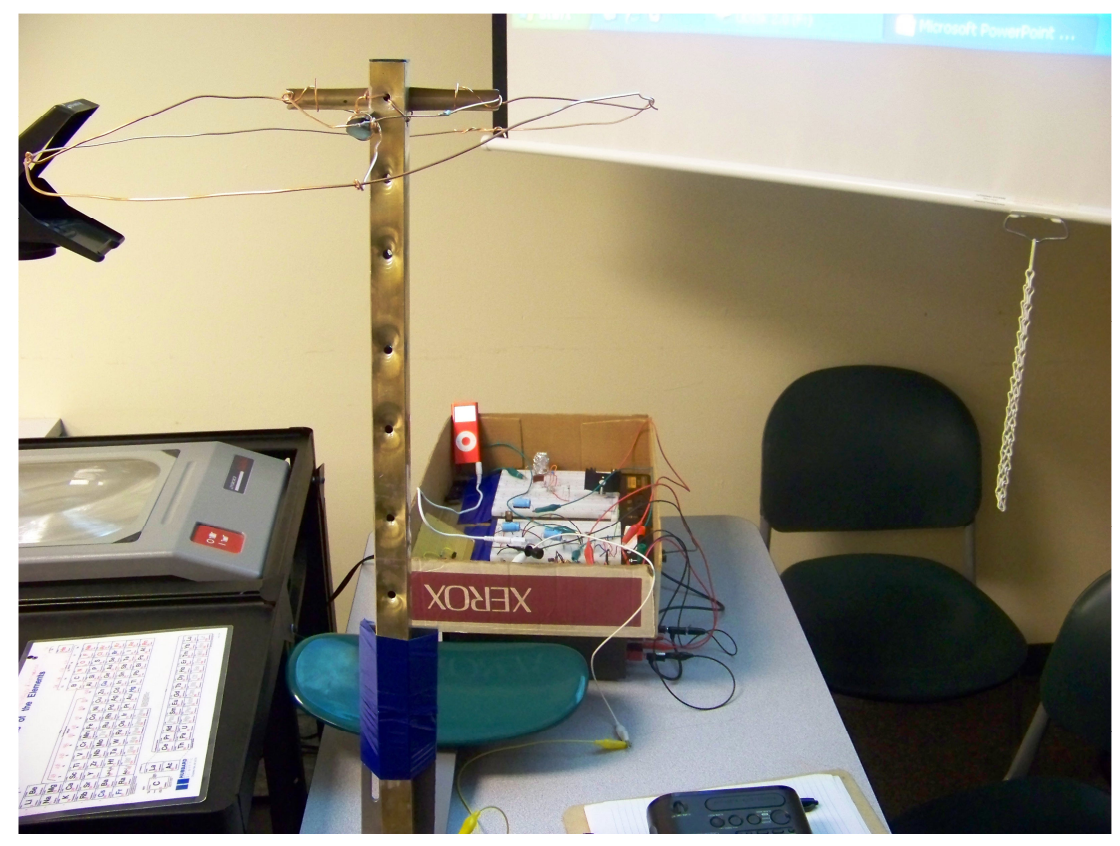

Figure \#1. AM transmitter circuit

Figure \# 2 shows another group transmitter project using a horizontal loaded antenna. 


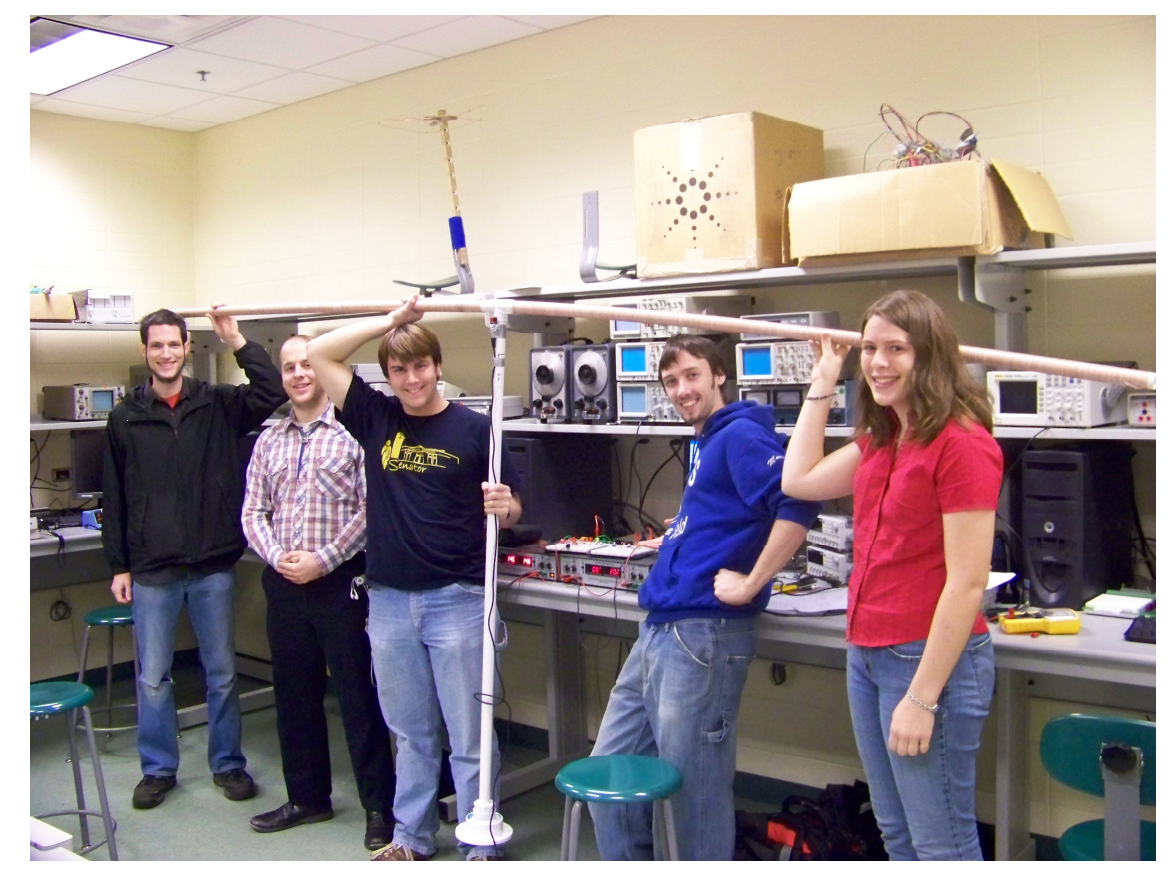

Figure \#2 AM transmitter circuit

\section{The AM receiver circuit}

The requirements for the design of the AM receiver circuits were also short and simple. A receiver capable of tuning to a fixed frequency between $550 \mathrm{KHZ}$ and $950 \mathrm{KHz}$. Amplifier stages built using BJT's. The following exception were made: students were able to use an antenna from an existing radio, for the IF (intermediate frequency) amplification stages integrated circuits were allowed, and for the audio amplification stage an LM386 IC was recommended. The design of the AM receiver circuit was divided into six major sections. Modules of each section were designed and developed separately. Once each individual module was working, the students had to interconnect all the modules together.

- Tuning circuit and input amplification stage

- Local oscillator circuit stage

- AM demodulator and mixing stage

- IF amplification stage

- Envelop detector and feedback stage

- Final signal amplification audio amplification stage

Figure \# 3 shows a picture of one of several of the circuit modules of one of the groups receiver project. 


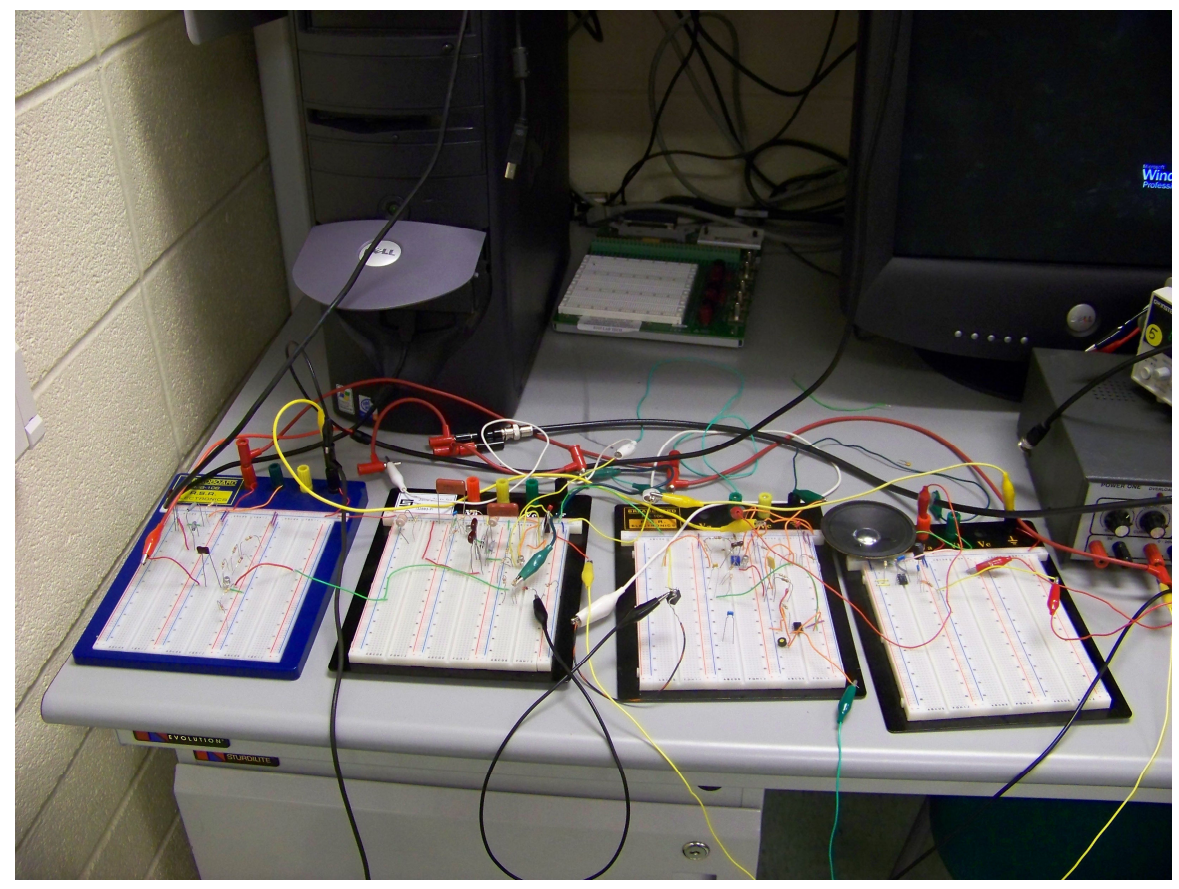

Figure \#3. AM receiver circuit

\section{Assessment}

The following graphs, labeled figure 4 and figure 5 represent the grades obtained by the students in the lecture course EEGR 3113 during the fall semesters of 2005 to 2008. These grades were calculated using the traditional grading tools such as quizzes, homework, designs, exams, project reports and oral presentations.

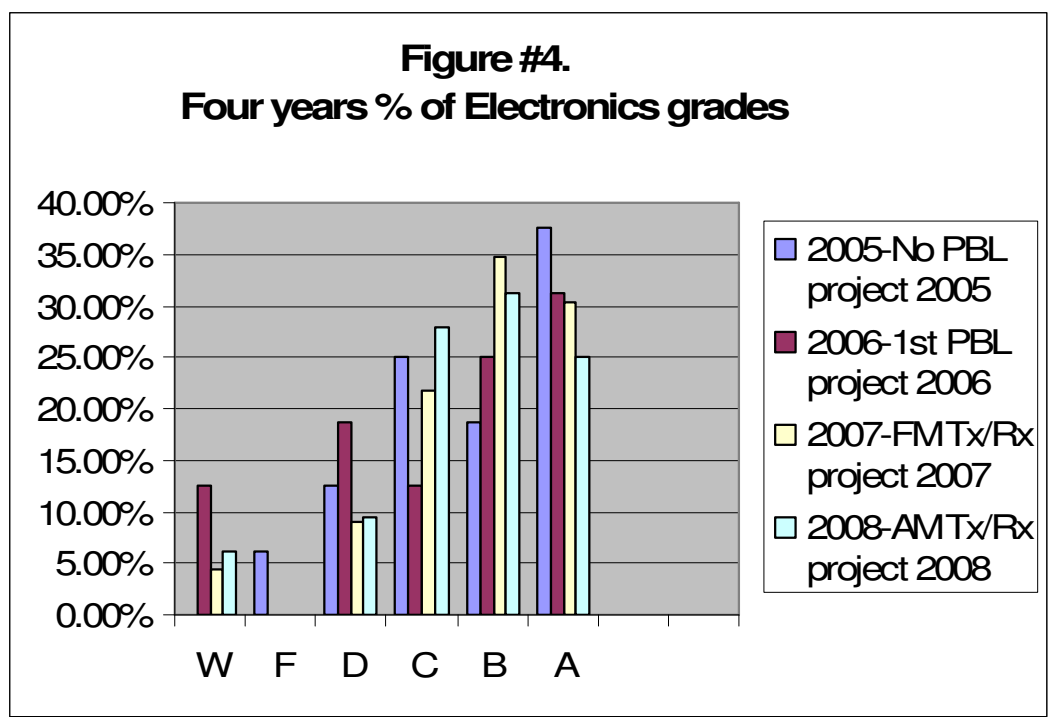

In figure \#4, the labels of the $\mathrm{X}$-axis correspond to $\mathrm{W}=$ withdraw, $\mathrm{F}<60,60<\mathrm{D}<70$, $70<\mathrm{C}<80,80<\mathrm{B}<90$, and $90<\mathrm{A}<100$. During 2005 one can see a larger number of 
students with a grade $\mathrm{C}$ and $\mathrm{A}$, and fewer students obtaining a B. After the introduction of the first PBL in 2006, the number of Bs increased and the number of Cs decreased, but the number of Ds also increased. In 2007 one sees a better trend, the number of students obtaining a grade of B is the largest, the number of As is still larger than the number of Cs and the number of Ds decreased. In 2008, the number of Bs is the largest, the number of As decreased about 5\% and the number of Cs increased about the same rate, but the number of students with Ds or failing the class remains lower less than $10 \%$

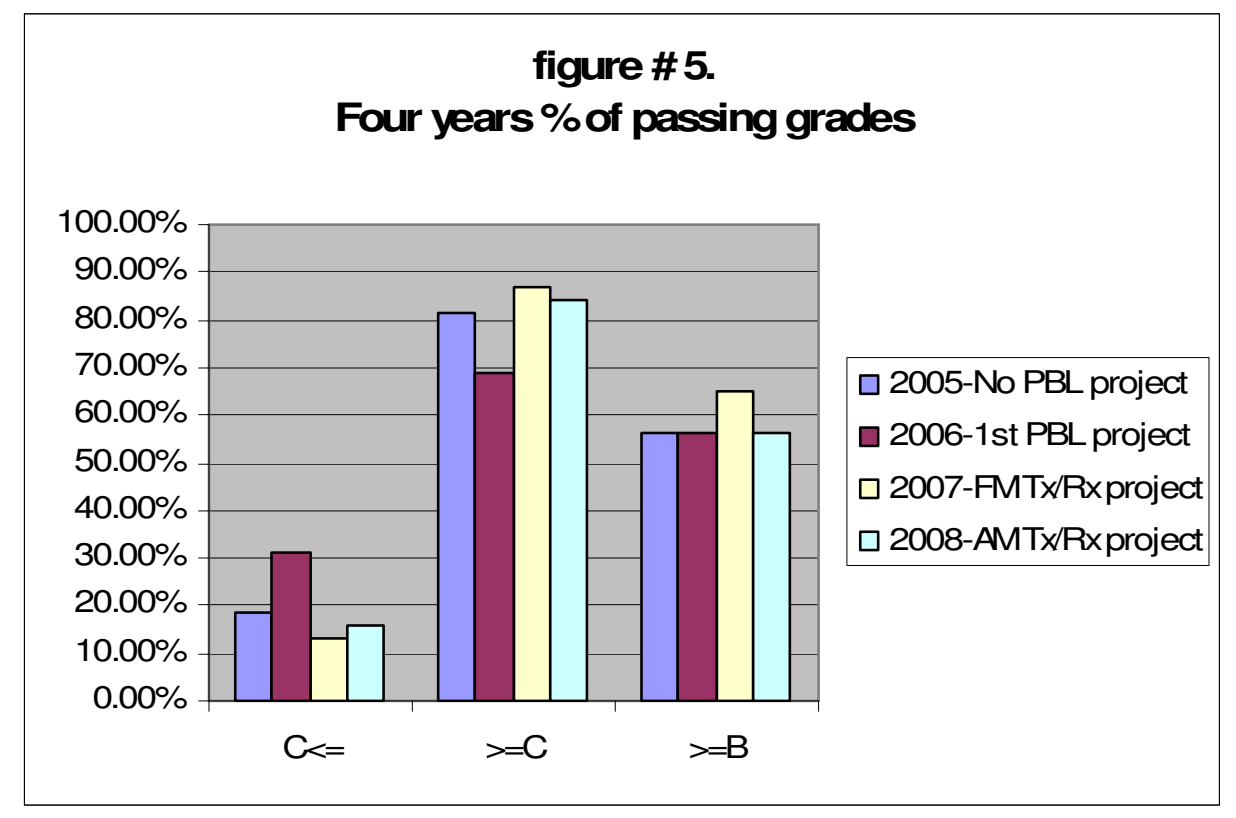

In figure \#5, our sample was divided in three groups. The first group is form with all the students with grades lower than $\mathrm{C}$, these includes all the students with grades of D, F and $\mathrm{W}$. The second group is form with all the students with grades better or equal than $\mathrm{C}$, and includes all the students with Cs, Bs, and As. And the third group is al the students with grades better or equal than B including those students with As.

From the graph in figure \#5, one can see that more than $85 \%$ of the students are passing electronics I with a grade better or equal than C, and from this $85 \%$ more than $55 \%$ are passing with a grade better or equal than B. And equally important, is that the number of students ending with grades lower than $\mathrm{C}$ has been reduced to less than $15 \%$ in the last two years.

The following graphs, labeled figure \# 6, \#7, \#8 and \#9, show the result of an anonymous survey passed at the end of the semester. In this survey students are asked to evaluate their understanding of analog electronic through their experiences with the labs in EEGR 3112 and the PBL project. Figures \#6, \#7, \#8 and \#9 show the results of the question pertaining only to the PBL project. A copy of the survey is attached in the appendix

The AM transmitter and receiver circuits dealt extensively with issues of impedance. In figure \#6, having around $47 \%$ of students responding false or neutral to their 
improvement of their understanding of impedance and its applications was the result of already having a clear understanding of it or as a consequence of dividing the AM project in modules; were students only took responsibility for their assigned module. The other $53 \%$ of students took part or were involved in the process of inter-connecting all the modules together. And this helped them to improve their understanding.

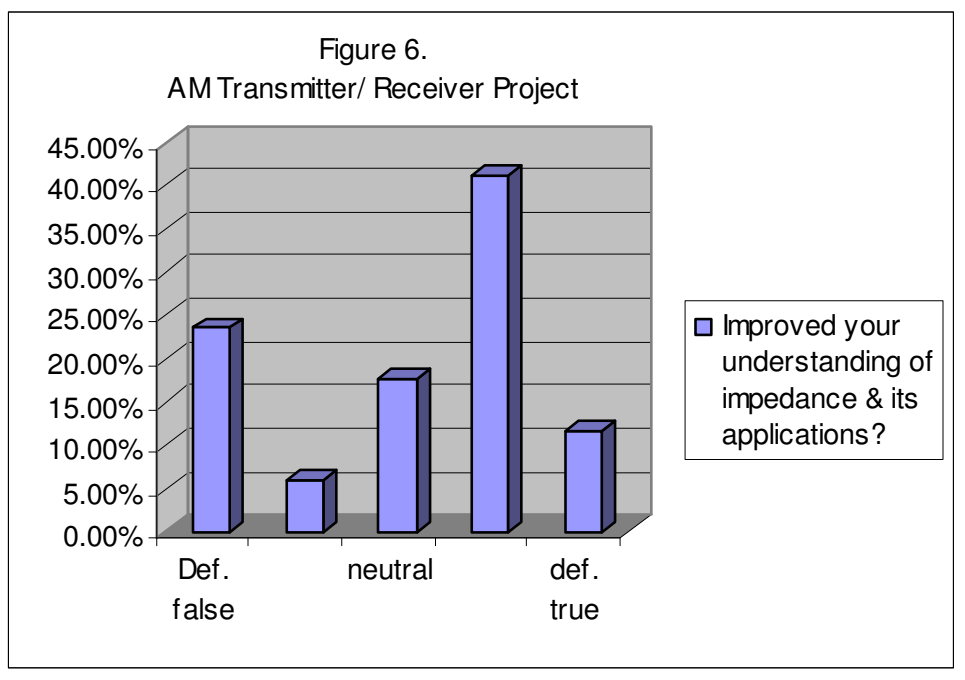

The AM transmitter and receiver circuits also dealt with the subject of resonance at its applications. In figure \#7, having around $42 \%$ of students responding false or neutral to their improvement of their understanding of it was the result of already having a clear understanding of it or as a consequence of working with modules that dealt only with audio or signal amplification. The other $58 \%$ of students worked with modules in which resonance was an essential part of it. Notice that the definitively false bar dropped to $5 \%$.

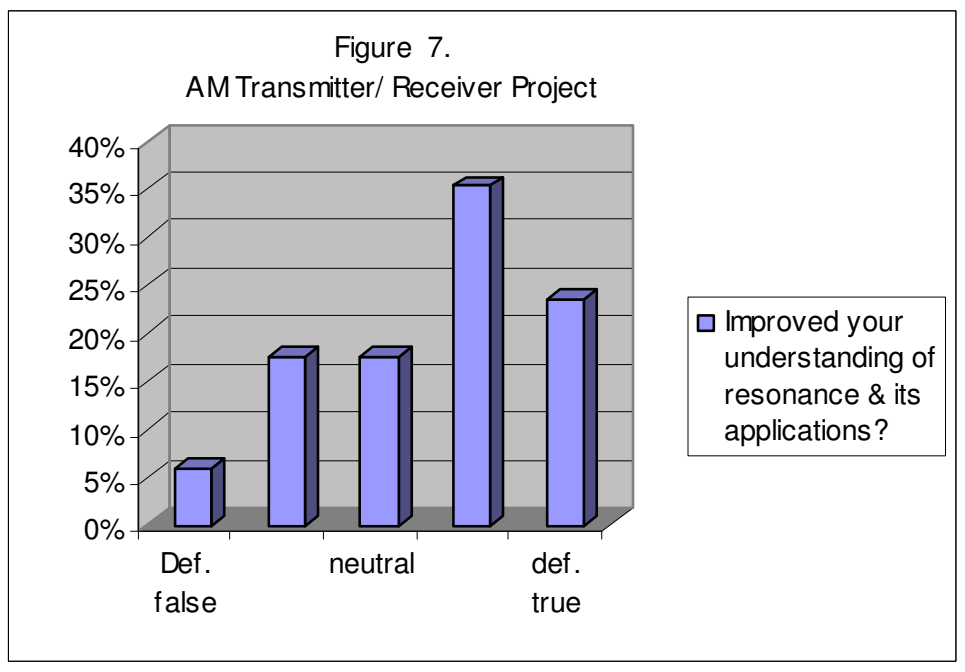

As a design requirement the AM transmitter and receiver circuits were required to be built using BJT's transistors. In figure \#8, having around $36 \%$ of students responding false or neutral to their improvement of their understanding of them was the result of 
already gaining a clear understanding through the regular electronics labs. The other $64 \%$ gained a better understanding by working with the AM circuits. Notice that the definitively false bar dropped this time to $0 \%$.

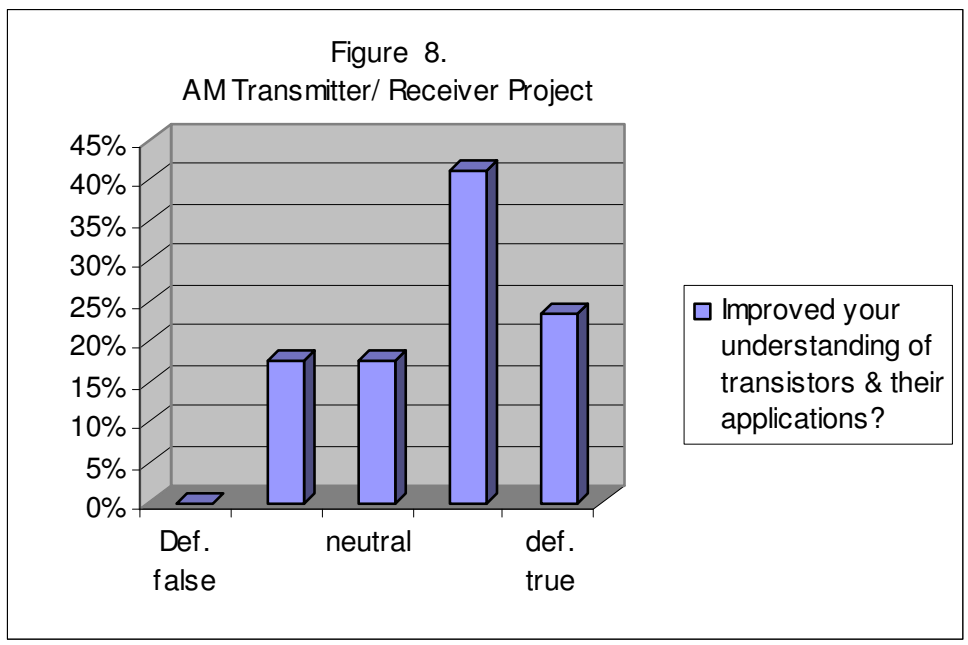

Now figure \# 9 deals with the subject of the PBL project. Having around $30 \%$ of students responding false or neutral to their improvement of their understanding of AM radios was the result of already having a clear understanding of radios or as a consequence of working with modules that dealt only with audio or signal amplification. $70 \%$ of the students gained a better understanding of AM radios through this project. Notice once more that the definitively false bar was equal to $0 \%$.

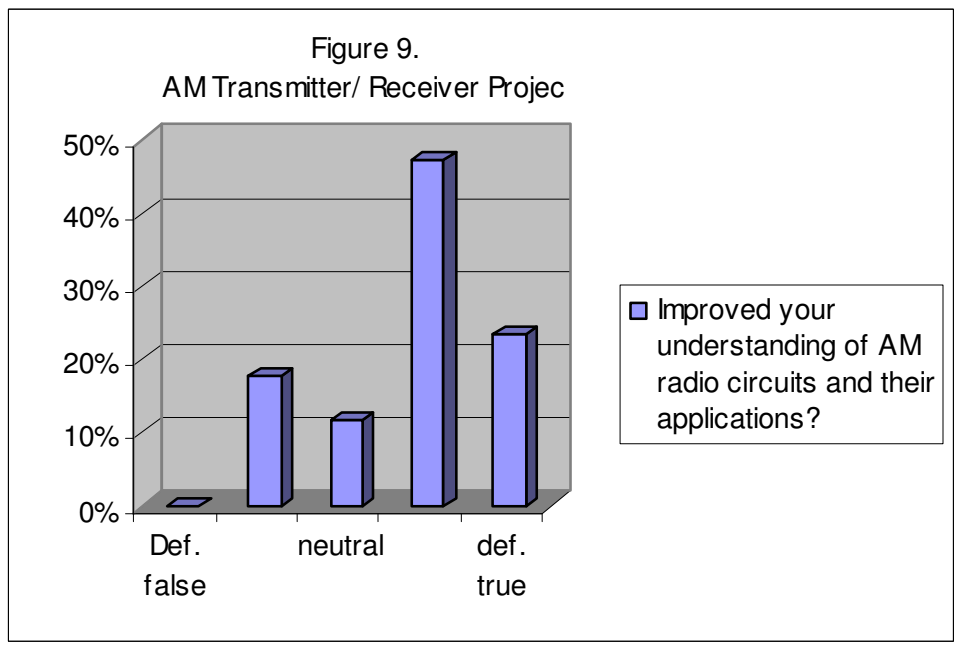

The last question of the survey was: "In a short sentence, tell us what you think about the FM transmitter/receiver project?" Here are some of the student's answers:

I though that the project was a very useful tool in applying what was learned in class. 
$\checkmark$ It was hard, but helped us understand (in general) the working parts of a radio receiver.

$\checkmark$ The project taught me a lot, though covering it more directly in class would have been helpful.

$\checkmark$ It was very hard, but I learned a lot about the components I worked on. (envelop detector \& audio amplifier).

$\checkmark$ I definitely learned a lot about AM communication theory as well as transistors, oscillators, and different diode applications. However, the project seemed to be a little beyond the scope of the class.

$\checkmark$ It was to difficult and did not apply to much of what we learned. I felt like we had to learn everything on our own and we learned in was of minimal help.

$\checkmark \quad$ It allowed me to learn a lot about AM transmission, however it would have been nice to be taught about the subject to improve understanding.

$\checkmark \quad$ I felt that the material covered in class was not sufficient in order to complete the assigned project or to understand the theory for the AM radio.

$\checkmark$ Because of the group dynamic, I felt like I didn't understand what was going on ever, and I didn't feel pressure to learn either. People were just trying to be friendly, but I gained nothing from the project as a result. To be fair, my hard wasn't in it either.

\section{Conclusions}

In our first project-based learning experience in 2006 it was learned, that when the students are given the opportunity to propose and select the project to work on, they will usually select a project that is within their current knowledge level, one that they think the can easily do. This generated undesired results. In our second PBL project in 2007, the instructor assigned a project believed to be at the proper level and adequately challenging to generate positive results. In this particular case, the students worked with FM transmitter and receiver electronic kits. The results showed an improvement in the student's learning, but we were not still satisfied, since the project was lacking on the design of the actual transmitter/ receiver circuit. So, in the fall semester of 2008 the PBL project included the design and implementation of an AM transmitter and an AM receiver circuit.

The objectives of this PBL project were:

1) apply their previous knowledge from Circuit I \& II courses,

The students applied circuit analysis techniques and their previous knowledge of inductance, capacitance, impedance, resonance, frequency response, amplification and feedback in the development of their AM circuit design and implemented the AM transmitter and receiver using basic circuits components.

2) apply the concepts learned from their concurrent Electronics lectures and predefined lab experiments, 
The students were able to apply their concurrent knowledge of electronics in the design and implementation of signal amplifiers, local oscillators, AM modulators, AM demodulators, frequency multipliers, AM mixers, AM detectors, and audio power amplifiers.

3) respond to the challenge to research, study and apply concepts from future Electronic Communication and RF theory courses, and

The student were challenged to learn amplitude modulation theory in order to design the AM tuning circuit, the local oscillator to generate the AM carrier frequency, the AM Modulator and demodulator, the amplification stages, the audio input and out amplification stages.

4) work in teams to complete tasks, meet deadlines, and deliver a working final product.

The students were able to work in teams to complete tasks, meet deadlines and only $50 \%$ of the groups were able to deliver a final working product, whereas the other $50 \%$ of the groups encounter problems with coupling the input/output stage of their circuit to the antenna.

Students divided the tasks of their projects in stages and worked in individual modules and each team member took responsibility for their module. Unfortunately, some of the students limited their learning and participation to their particular module and missed on the opportunity to learn and enhance their understanding of the subject. On the other hand, as is the case in many projects few students eagerly embraced the project and got involved in helping in the developing of all stages and at the end; they were the ones that benefit the most.

After evaluating the results of our third PBL project one can come to the conclusion that even with the presence of some difficulties or variables not accounted for in the analysis of this experience, having students work in PBL projects helped them enhance their learning of analog electronics. For the next year LPB project, methods to prepare the students for the project, handouts and reports required are being review, and measures will be taken to ensure that must of the students participate and contribute equally to their projects.

\section{Bibliography}

[1] Leiffer, P.R., Graff R.W. and Gonzalez R.V., "Five Curriculum Tools to Enhance Interdisciplinary Teamwork," Proceedings of the 2005 American Society for Engineering Education Annual Conference and Exposition.

[2] Northern J. and Fuller, J., "Project-Based Learning for a Digital Circuits Design Sequence at HBCUS", Proceedings of the 2007 American Society for Engineering Education Annual Conference and Exposition, June 24-27, 2007, Honolulu, Hawaii. 
[3] Ortiz, O and Leiffer, P., "Motivating Student Effort in Electronics by Working with Projects of Personal Interest", Proceedings of the 2007 American Society for Engineering Education Annual Conference and Exposition, June 24-27, 2007, Honolulu, Hawaii.

[4] Ortiz, O and Leiffer, P., "Learning Analog Electronics Through Project-based Investigation of FM Communication Circuits", Proceedings of the 2008 American Society for Engineering Education Annual Conference and Exposition, June 24-27, 2008, Pittsburgh, Pennsylvania. 


\begin{tabular}{|c|c|c|c|c|c|}
\hline \multicolumn{6}{|c|}{ Appendix } \\
\hline & \multicolumn{5}{|c|}{$\begin{array}{l}\text { STUDENT EVALUATION OF ELECTRONIC PROJECT EFFECTIVENESS } \\
\text { "Participation in this survey is voluntary. The results of the survey will be accumulated and shared } \\
\text { with ASEE members only. No individual results will be reported on or connected to any faculty, staff } \\
\text { or student respondent. Do not sign your name." }\end{array}$} \\
\hline \multirow[t]{2}{*}{1} & \multicolumn{5}{|c|}{ Did the introductory diode's lab improve your understanding of diodes? } \\
\hline & \begin{tabular}{l|l} 
Definitely False \\
\end{tabular} & Mostly False & Neutral & Mostly True & Definitely true \\
\hline \multirow[t]{2}{*}{2} & \multicolumn{5}{|c|}{ Did the diode's IV curves lab improve your understanding of diodes? } \\
\hline & \begin{tabular}{l|l} 
& Definitely False
\end{tabular} & Mostly False & Neutral & Mostly True & Definitely true \\
\hline \multirow[t]{2}{*}{3} & \multicolumn{5}{|c|}{ Did the diode clippers and clampers lab improve your understanding of diodes and their applications? } \\
\hline & \begin{tabular}{l|l|} 
Definitely False \\
\end{tabular} & Mostly False & Neutral & Mostly True & Definitely true \\
\hline \multirow[t]{2}{*}{4} & \multicolumn{5}{|c|}{ Did the use of zener diodes improve your understanding of voltage regulation? } \\
\hline & Definitely False & Mostly False & Neutral & Mostly True & Definitely true \\
\hline \multirow[t]{2}{*}{5} & \multicolumn{5}{|c|}{$\begin{array}{l}\text { Did the RC and RLC frequency response labs improve your understanding of how electronic } \\
\text { components react to changes in frequencies and can be used as filters? }\end{array}$} \\
\hline & \begin{tabular}{l|l} 
& Definitely False \\
\end{tabular} & Mostly False & Neutral & Mostly True & Definitely true \\
\hline \multirow[t]{2}{*}{6} & \multicolumn{5}{|c|}{ Did the transistor's labs experiments improve your understanding of transistors and their applications? } \\
\hline & Definitely False & Mostly False & Neutral & Mostly True & Definitely true \\
\hline \multirow[t]{2}{*}{7} & \multicolumn{5}{|c|}{ Did the Op-Amp's labs experiments improve your understanding of Op-Amps and their applications? } \\
\hline & \begin{tabular}{l|l} 
Definitely False \\
\end{tabular} & Mostly False & Neutral & Mostly True & Definitely true \\
\hline \multirow[t]{2}{*}{8} & \multicolumn{5}{|c|}{ Did the MOSFET's lab experiment improve your understanding of MOSFETS and their applications? } \\
\hline & \begin{tabular}{l|l} 
& Definitely False \\
\end{tabular} & Mostly False & Neutral & Mostly True & Definitely true \\
\hline \multirow[t]{2}{*}{9} & \multicolumn{5}{|c|}{ Did the AM transmitter/receiver project improve your understanding of impedance \& its applications? } \\
\hline & Definitely False & Mostly False & Neutral & Mostly True & Definitely true \\
\hline \multirow[t]{2}{*}{10} & \multicolumn{5}{|c|}{ Did the AM transmitter/receiver project improve your understanding of resonance \& its applications? } \\
\hline & \begin{tabular}{l|l} 
& Definitely False \\
\end{tabular} & Mostly False & Neutral & Mostly True & Definitely true \\
\hline \multirow[t]{2}{*}{11} & \multicolumn{5}{|c|}{$\begin{array}{l}\text { Did the AM transmitter/receiver project improve your understanding of transistors \& their } \\
\text { applications? }\end{array}$} \\
\hline & Definitely False & Mostly False & Neutral & Mostly True & Definitely true \\
\hline \multirow[t]{2}{*}{12} & \multicolumn{5}{|c|}{$\begin{array}{l}\text { Did the AM transmitter/receiver project improve your understanding of AM radio circuits and their } \\
\text { applications? }\end{array}$} \\
\hline & Definitely False & Mostly False & Neutral & Mostly True & Definitely true \\
\hline 13 & \multicolumn{5}{|c|}{ In a short sentence, tell us what do you think about the AM transmitter/receiver project? } \\
\hline
\end{tabular}




\section{Study and research assignment for members of the Transmitter group}

The following are the basic stages for the AM transmitter:

1_ The microphone and input signal amplification

2_ The oscillator

3_ The AM Modulator

4_ Power output amplification

$5 \_$Antenna and impedance matching

You need to research and study how an AM transmitter works. Then you need to design your own transmitter using the analog electronic components studied in class. Divided the design in the stages mentioned above and build modules for each stage. Once each stage is functional and working connect them all together.

You should present your project following the guidelines provided for a formal report and prepare a power point to present your project to the class.

\section{Study and research assignment for members of the Receiver group}

The following are the basic stages for the AM receiver:

1_ AM RF tuner/ amplifier

2_ The oscillator

3_ The AM Mixer

4_ Intermediate frequency "IF" amplifier stage

$5 \_$AM detector

6_ Automatic Gain control

6_ Audio amplifier

You need to research and study how an AM receiver works. Then you need to design your own receiver using the analog electronic components studied in class. Divided the design in the stages mentioned above and build modules for each stage. Once each stage is functional and working connect them all together.

You should present your project following the guidelines provided for a formal report and prepare a power point to present your project to the class. 